\title{
Phytochemical Screening, Antioxidant and Antibacterial Activities of the Root Extract of Cyphostemma adenocaule (Steud. ex A. Rich.) Wild \& R.B.Drumm
}

\author{
Abdulbasit Haliru Yakubu1,3,*, Mohammed Mustapha Mohammed ${ }^{2}$, \\ Abdulqadir Bukar Bababe ${ }^{1}$, Hassan Yesufu Braimah ${ }^{1}$ \\ ${ }^{1}$ Department of Pharmaceutical Chemistry, PMB 1069, Faculty of Pharmacy, University of Maiduguri, Borno State, Nigeria. \\ ${ }^{2}$ Department of Microbiology, Faculty of Science, PMB 1069, University of Maiduguri, Maiduguri, Nigeria. \\ ${ }^{3}$ Department of Pharmaceutical Service, PMP 1414, University of Maiduguri Teaching Hospital, Maiduguri, Nigeria. \\ Corresponding author* \\ pharmahy071@gmail.com
}

Manuscript received: 13 September 2021. Revision accepted: 10 October, 2021. Published: 11 October, 2021.

\begin{abstract}
Plant secondary metabolites have provided important bioactive principles for developing new lead compounds. Within their confinement, they exhibit unique chemical diversity, which influences their diverse biological properties. The Vitaceae family is known for its potent antioxidant and antibacterial phytoconstituents, among other biological properties. Cyphostemma adenocaule is one of the family members explored for its ethnomedicinal properties. This study undertook the evaluation of the phytochemical, antioxidant, and antibacterial properties of the root extract of Cyphostemma adenocaule. Preliminary phytochemical screening revealed the presence of flavonoids, alkaloids, carbohydrates \& glycoside, saponins, and tannins. The methanol root extract had the highest activity in the DPPH assay, providing $\mathrm{IC}_{50}\left(50 \%\right.$ inhibition) of $10.87 \mu \mathrm{g} / \mathrm{ml}$, followed by $\mathrm{n}-\mathrm{Hexane}\left(\mathrm{IC}_{50} 74.10 \mu \mathrm{g} / \mathrm{ml}\right.$ ) and chloroform (IC $\left.5074.31 \mu \mathrm{g} / \mathrm{ml}\right)$ extract. In the antibacterial assay, the chloroform extract was active against E. coli $(24.00 \pm 0.15)$ and had moderate activity against Staph. aureus $(12.5 \pm 0.18)$. The $n-H e x a n e$ extract was completely inactive against the test organisms while the methanol extract showed poor activity against the test organisms. The present study adds to the existing literature on Cyphostemma adenocaule with scientific evidence into its biological properties.
\end{abstract}

Keywords: Cyphostemma adenocaule; Phytochemical screening; antioxidant and antibacterial activity.

Abbreviations: CA1 - Cyphostemma adenocaule 1; CHCl3 - Chloroform; COSY - Correlation Spectroscopy; DEPT - Distortions Enhancement by Polarization Transfer; EtA - Ethyl acetate; HMBC - Heteronuclear Multiple Bond Correlation; HSQC - Heteronuclear Single Quantum Correlation; KHSO4 - Potassium bisulphide; MeOH - Methanol; MOA - Mechanism of Action; nHex - Hexane; NMR - Nuclear Magnetic Resonance; TLC - Thin Layer Chromatography; WHO - World Health Organization.

\section{INTRODUCTION}

Natural products have been in existence for ages and evolved with unique chemical diversity, which results in their diverse biological activities and drug-like properties. These compounds present as important resources for developing new lead compounds and scaffolds (Galm \& Shen, 2007).

Morphine from the opium poppy plant is considered the first pharmacologically active compound isolated by Friedrich Sertürner (Hamilton \& Baskett, 2000; Joo, 2014).

Natural products are important for the development of new drugs, and these products have been in constant use. Drugs used as anticancer, antihypertensive, and antimigraine medication, have benefited greatly from natural products (Joo, 2014; Newman et al., 2003)
Plants have been part of traditional medicine systems, which have been used for thousands of years (Iwu, 2014). These plant-based systems continue to play an essential role in health care, and it has been estimated by the World Health Organization (WHO) that approximately $80 \%$ of the world's inhabitants rely mainly on traditional medicines for their primary health care (WHO, 2017)

Cyphostemma adenocaule (Steud. ex A. Rich.) Wild \& R.B.Drumm is a climbing, scrambling, or trailing herb that belongs to the Vitaceae family (Bello et al., 2019; Wickens \& Burkill, 1986) and is locally known as yáákùwár fátààké (Hausa, Nigeria) (Wickens \& Burkill, 1986). The plant is a popular, non-cultivated vegetable eaten in many parts of Africa i.e., Nigeria, Ghana, Congo, Uganda, Ethiopia, and Eritrea (Bello et al., 2019). The plant had been documented for its 
ethnomedicinal value, with a comprehensive review given by Bello and colleagues (2019).

The effectivity of Plant bioactive compounds against oxidative stress-related diseases and as an anti-infective had been well explored. This study entails investigating the phytochemical, antioxidant, and antibacterial properties of the root extracts of $C$. adenocaule by employing standard protocol. The results from the study will justify the ethnomedicinal uses of the plant and underscore its potentials as a source of antioxidants and antimicrobial agents.

\section{MATERIALS AND METHOD}

\section{Plant Collection and Identification}

Fresh root parts of $C$. adenocaule were collected aseptically in July 2019 from Shuwarin town, Dutse LGA, Jigawa State, Nigeria, and identified at the Medicinal Botany section, of the Department of Biology, Ahmadu Bello University, Zaria, Nigeria.

\section{Preparation of Plant Extract and Its Fractions}

The preparation of plant material and fractions employed in our previous work on $C$. adenacaule was adopted with modifications (Yakubu et al., 2020). In this study, one and a half kilograms $(1.5 \mathrm{~kg})$ of the pulverized sample material was extracted with Hexane, Chloroform, and Methanol.

\section{Preliminary Phytochemical Screening}

Phytochemical screening was carried out on the crude extracts to detect the presence of plant secondary metabolites; alkaloids, anthraquinones, flavonoids, glycosides, steroids, tannins, terpenoids, and carbohydrates using standard procedures as described in the literature (Brain, KR and Turner, 1975; Evans, 2009; Markham, 1982; Sofowora, 1996; Vishnoi, 2009).

\section{Biological Activity \\ Test for Antioxidant Activity: DPPH Assay}

The radical scavenging potential was done using DPPH assay (Brand-Williams et al., 1995). $3 \mathrm{~mL}$ of $0.004 \%$ DPPH working solution (prepared using DPPH stock solution and methanol in correct proportions to give 0.899 abs) was added per every $100 \mu \mathrm{L}$ of different concentrations of the extract and incubated at $37{ }^{\circ} \mathrm{C}$ for 30 minutes in dark. Then absorbance was taken at 517 $\mathrm{nm}$ wavelength in a UV spectrophotometer. The negative control contained $100 \mu \mathrm{L}$ of methanol in place of the sample solution.

The percentage antioxidant inhibition (AI) was obtained by the equation:

$\% \mathrm{AI}=$ Control $(\mathrm{Abs})-$ Sample $(\mathrm{Abs}) \div$ Control $(\mathrm{Abs}) \times 100$
Ascorbic acid (AA) was used as the positive control. Inhibition curves were made and $\mathrm{IC}_{50}$ value per sample was calculated.

\section{Antimicrobial Assay \\ Test Organisms}

The organisms employed in this study are; Escherichia coli, Pseudomonas aeruginosa, staphylococcus aureus, and streptococcus epidermis, clinical isolates got from the Microbiology department, University of Maiduguri, and were stored at $2-8{ }^{\circ} \mathrm{C}$ until required.

\section{Preparation of Extract solutions for Pathogenic Assay}

A stock solution of the extracts was prepared by dissolving $10 \mathrm{~g}$ of extract in $10 \mathrm{~mL}$ of distilled water, and a $1000 \mathrm{mg} / \mathrm{mL}$ solution was obtained. A two-fold serial dilution was carried out to obtain working solutions of varying concentrations.

\section{Preparation of Test Organisms}

Test organisms cultured for 24 hours were suspended in a sterile bottle containing pure broth. Normal saline was added gradually to it and the turbidity was observed and compared to that of 0.5 Mcfarland standard which corresponds to approximately $10^{8}$ cells $/ \mathrm{mL}$. This was then diluted to produce $10^{6}$ cells $/ \mathrm{mL}$ and used in the experiments. The dilution ratio was 1:1000 and 1:1500 for Gram-positive and Gram-negative organisms respectively (Usman et al., 2009).

\section{Preparation of Agar Plates}

Nutrient agar was prepared accurately to the manufacturer's specification (i.e. by dissolving $18.5 \mathrm{~g}$ powder in $500 \mathrm{~mL}$ of distilled water) and sterilized at $121{ }^{\circ} \mathrm{C}$ for $15 \mathrm{~min}$. The sterilized agar was allowed to cool to $50{ }^{\circ} \mathrm{C}$ in a water bath. The test organism $(1 \mathrm{~mL})$ $\left(10^{6}\right.$ cells $\left./ \mathrm{mL}\right)$ was inoculated into pre-labeled Petri plates (90 mm diameter), then $19 \mathrm{~mL}$ of the molten agar was added to each Petri plate, shacked, and allowed to sit at room temperature on a flat surface.

\section{Antimicrobial Susceptibility Assay (agar well diffusion method)}

The antibacterial activity of the crude extracts was determined by following the agar-well diffusion method described by Igbinosa and colleagues (Igbinosa et al., 2009) with modification. The bacterial isolates were grown for $18 \mathrm{~h}$ in a nutrient broth and standardized to $0.5 \mathrm{McF}$ arland standards $\left(106 \mathrm{cfuml}^{-1}\right)$. Two hundred microliter of the standardized cell suspensions were spread on Mueller-Hinton agar (Oxoid) and wells were bored into the agar using a sterile $6 \mathrm{~mm}$ diameter cork borer. Approximately $100 \mu \mathrm{l}$ of the crude extract at 100 , 75,50 , and $25 \mathrm{mgml}^{-1}$ were introduced into the wells, allowed to stand at room temperature for about $2 \mathrm{hr}$, and then incubated at $37^{\circ} \mathrm{C}$. Controls were set up in parallel 
using the solvents that were used to reconstitute the extract. After $24 \mathrm{hr}$, the plates were observed for the zones of inhibition. The effects were compared with those of Ciprofloxacin at a concentration of $5 \mathrm{mg} / \mathrm{ml}$. Antibacterial activity was evaluated by measuring the diameters of zones of growth inhibition in triplicates and results were presented as Mean \pm SEM.

\section{Statistical Analysis}

The obtained antioxidant and antibacterial results were expressed in mean \pm standard error with observation recorded in triplicates. Analysis of variance for individual parameters was performed based on mean values to determine the significance at $p<0.05$ using SPPS v20. Regression analysis was deployed to calculate and obtain the $\mathrm{IC}_{50}$ from the regression equation using Excel 2016.

\section{Percentage Yield}

In this experiment, $1.5 \mathrm{~kg}$ of the resultant size reduced root powder of $C$. adenocaule was used. The $\mathrm{MeOH}$ extract showed the highest yield of $44.6 \mathrm{~g}$. The percentage yield is given in the Table 1

Table 1. Percentage yield of $C$. adenocaule root extracts.

\begin{tabular}{lll}
\hline Extract & Weight of extract $(\mathbf{g})$ & Percentage $(\%)$ yield \\
\hline nHex & 5.4 & 0.36 \\
$\mathrm{CHCL}_{3}$ & 12.5 & 0.83 \\
$\mathrm{MeOH}$ & 44.6 & 2.97 \\
\hline
\end{tabular}

Phytochemical Screening of Root Extract of $C$. adenocaule.

The result for the preliminary Phytochemical screening of root Extract of $C$. adenocaule is shown in Table 2.

Table 2. Preliminary Phytochemical screening of Methanolic extract of $C$. adenocaule.

\begin{tabular}{|c|c|c|c|c|}
\hline \multirow{2}{*}{ Phytoconstituent } & \multirow{2}{*}{ Test } & \multicolumn{3}{|c|}{ Result } \\
\hline & & nHexane & Chloroform & Methanol \\
\hline \multirow[t]{2}{*}{ Alkaloids } & Dragendorff's & + & + & + \\
\hline & Mayer's & + & + & + \\
\hline \multicolumn{5}{|l|}{ Anthraquinones } \\
\hline Free- anthraquinones & Borntrager's & - & + & - \\
\hline Combine anthraquinones & Borntrager's & - & - & - \\
\hline \multicolumn{5}{|l|}{ Carbohydrates } \\
\hline General test & Molisch's & + & + & + \\
\hline Monosaccharide & Barfoed's & + & + & + \\
\hline Free reducing sugar & Fehling's & - & + & + \\
\hline Combine reducing sugar & Fehling's & - & - & + \\
\hline \multicolumn{5}{|l|}{ Cardiac glycosides } \\
\hline Steroidal nucleus & Salkowsi's & - & + & + \\
\hline Steroidal nucleus & Liebermann-Buchard's & - & + & + \\
\hline Terpenoids & & - & - & + \\
\hline \multirow[t]{4}{*}{ Flavonoids } & Lead acetate & - & + & \\
\hline & Ferric Chloride & - & + & + \\
\hline & Shinoda's & - & + & + \\
\hline & Sodium Hydroxide & - & + & + \\
\hline Saponins glycosides & Frothing & - & - & + \\
\hline \multirow[t]{2}{*}{ Tannins } & Ferric Chloride & + & - & + \\
\hline & Lead acetate & + & - & + \\
\hline
\end{tabular}

\section{Biological Activity}

\section{DPPH assay: In-vitro Antioxidant Activity}

Table 3. In vitro antioxidant activity (DPPH assay) of C. adenocaule root extract fractions.

\begin{tabular}{lllll}
\hline \multirow{2}{*}{ Concentration $(\boldsymbol{\mu g} / \mathbf{m l})$} & \multicolumn{4}{c}{ \% of DPPH scavenging activity } \\
\cline { 2 - 5 } & $\mathbf{n H e x}$ & $\mathbf{C H C l}_{\mathbf{3}}$ & $\mathbf{M e O H}$ & $\mathbf{A A}$ \\
\hline 6.25 & 22.8 & 33.5 & 32.8 & 46.5 \\
12.5 & 29.9 & 35.9 & 55.2 & 53.7 \\
25 & 36.8 & 39.4 & 67.2 & 64.1 \\
50 & 40.5 & 44.6 & 79.3 & 77.3 \\
100 & 55.2 & 50.9 & 97.2 & 96.8 \\
$\mathrm{IC}_{50}$ & 74.1 & 74.6 & 10.87 & 4.51 \\
\hline
\end{tabular}

Key: AA: ascorbic acid, $\mathrm{CHCl}_{3}$ : Chloroform extract, nHex: n-Hexane extract, $\mathrm{MeOH}$ : Methanol extract
Results of the in vitro antioxidant assay (in $\mathrm{IC}_{50}$ ) of the crude root extracts of $C$. adenocaule are given in Table 3 below. The $\mathrm{MeOH}$ extract showed relatively invitro DPPH scavenging activity compared to other extracts. 


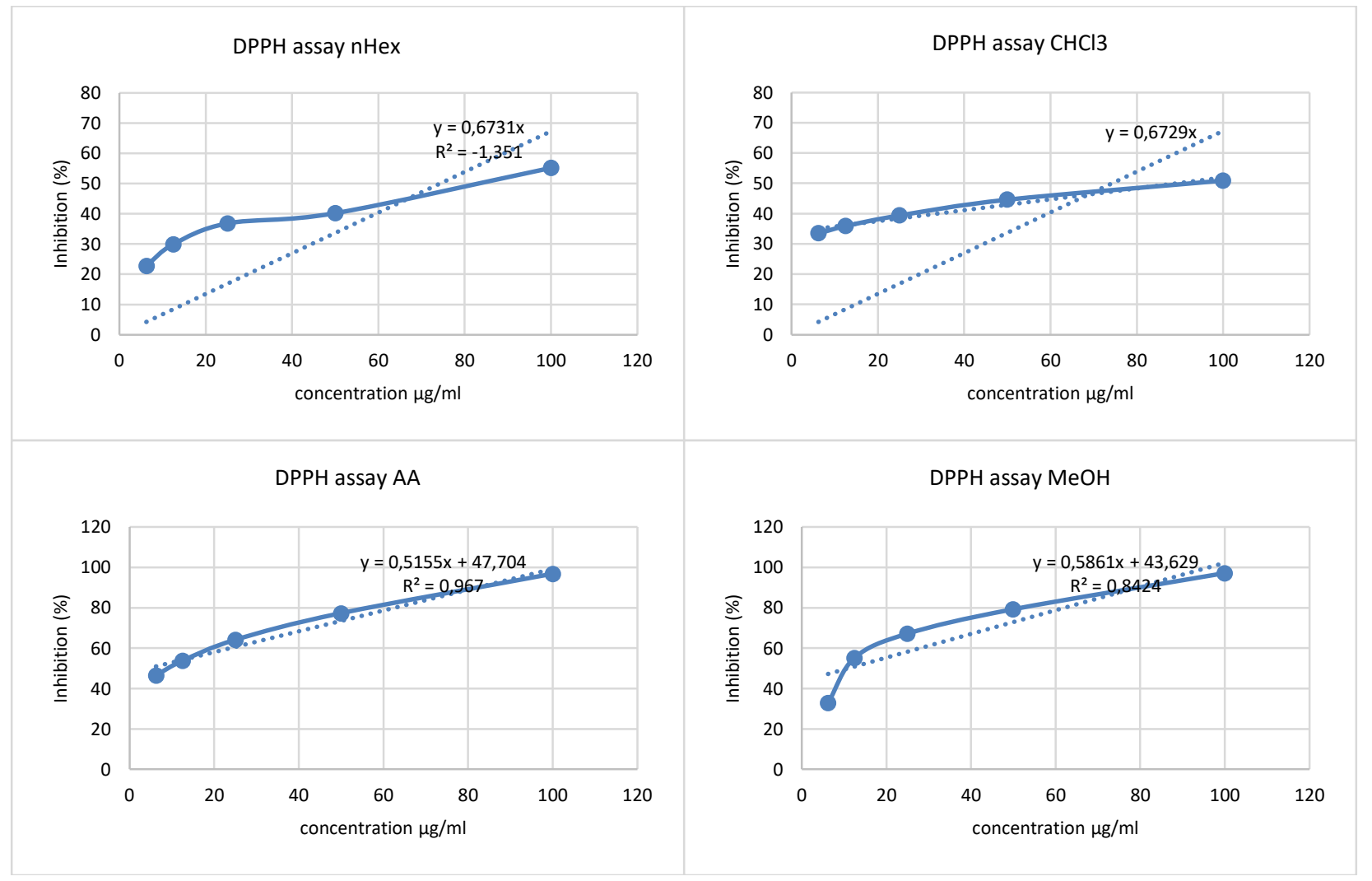

Figure 1. DPPH assay; $\mathrm{IC}_{50}$ extrapolation graph of nHex, $\mathrm{CHCl}_{3}$, and $\mathrm{MeOH}$ extracts of $C$. adenocaule.

\section{Antimicrobial Susceptibility Assay}

The $\mathrm{CHCl}_{3}$ showed the highest activity against the test organism. The result of the in-vitro antimicrobial susceptibility assay is given in Table 4.

Table 4. In vitro antimicrobial activity of $C$. adenocaule extract.

\begin{tabular}{|c|c|c|c|c|c|}
\hline \multirow{2}{*}{ Concentration $(\mathrm{mg} / \mathrm{ml})$} & \multirow{2}{*}{ Test organism } & \multicolumn{4}{|c|}{ Extracts } \\
\hline & & Hex & $\mathrm{CHCl}_{3}$ & $\mathrm{MeOH}$ & CIP(5mg/ml) \\
\hline \multirow{5}{*}{100} & E. coli & $00.00 \pm 0.00$ & $24.00 \pm 0.15$ & $0.10 \pm 0.02$ & $31.00 \pm 0.75$ \\
\hline & P. aeruginosa & $00.00 \pm 0.00$ & $2.00 \pm 0.02$ & $2.00 \pm 0.00$ & $27.30 \pm 0.41$ \\
\hline & Stap. aureus & $00.00 \pm 0.00$ & $12.50 \pm 0.18$ & $5.50 \pm 0.13$ & $29.70 \pm 0.17$ \\
\hline & S. epidermis & $00.00 \pm 0.00$ & $5.50 \pm 0.07$ & $1.5 .00 \pm 0.1$ & $25.02 \pm 0.84$ \\
\hline & E. coli & $00.00 \pm 0.00$ & $12.00 \pm 0.15$ & $0.10 \pm 0.00$ & - \\
\hline \multirow{3}{*}{75} & P. aeruginosa & $00.00 \pm 0.00$ & $1.00 \pm 0.15$ & $2.00 \pm 0.32$ & - \\
\hline & Stap. aureus & $00.00 \pm 0.00$ & $13.50 \pm 0.4$ & $2.00 \pm 0.01$ & - \\
\hline & S. epidermis & $00.00 \pm 0.00$ & $7.50 \pm 0.12$ & $1.0 .00 \pm 0.00$ & - \\
\hline \multirow{5}{*}{50} & E. coli & $00.00 \pm 0.00$ & $4.50 \pm 0.2$ & $0.10 \pm 0.00$ & - \\
\hline & P. aeruginosa & $00.00 \pm 0.00$ & $0.00 \pm 0.00$ & $0.00 \pm 000$ & - \\
\hline & Stap. aureus & $00.00 \pm 0.00$ & $9.10 \pm 0.16$ & $2.00 \pm 0.10$ & - \\
\hline & S. epidermis & $00.00 \pm 0.00$ & $2.60 \pm 0.05$ & $1.70 \pm 0.18$ & - \\
\hline & E. coli & $00.00 \pm 0.00$ & $3.00 \pm 0.21$ & $0.10 \pm 0.00$ & - \\
\hline \multirow{3}{*}{25} & P. aeruginosa & $00.00 \pm 0.00$ & $0.00 \pm 0.00$ & $0.20 \pm 0.00$ & - \\
\hline & Stap. aureus & $00.00 \pm 0.00$ & $2.50 \pm 0.4$ & $1.00 \pm 0.10$ & - \\
\hline & S. epidermis & $00.00 \pm 0.00$ & $1.00 \pm 0.00$ & $1.50 \pm 0.00$ & - \\
\hline
\end{tabular}

Key: CIP: ciprofloxacin

\section{DISCUSSION}

Many solvents including $\mathrm{Hex}, \mathrm{CHCl}_{3}$, and $\mathrm{MeOH}$ had been employed for the extraction of bioactive plant principles. $\mathrm{MeOH}$ had shown effective as an extraction solvent in many plant drug analyses especially in the isolation of phenolics and flavonoids content (Do et al., 2014; Truong et al., 2019). The percentage yield result 
from this study shows $\mathrm{MeOH}$ to be with the highest extraction yield of $2.97 \%$, followed by $\mathrm{CHCl}_{3}(0.83 \%)$ and $\mathrm{nHex}(0.36 \%)$ respectively. (Table 1$)$.

Phytochemical screening of $C$. adenocaule using standard methods revealed the presence of alkaloids, carbohydrates, saponins, and tannins in the nHex extract. Flavonoids, carbohydrates and glycoside, alkaloids, saponins, terpenoids, and tannins were present in both the $\mathrm{CHCl}_{3}$ and $\mathrm{MeOH}$ extracts (Table 4). Similar results were reported by Akinwunmi and colleagues on the phytochemical screening of the ethanol root extract of $C$. adenocaule (Akinwunmi et al., 2015).

DPPH assay remains one of the commonly employed methods for the analysis of the antioxidant activity of plant phytochemicals and employs spectrophotometric application. The ability of a test compound to scavenge DPPH radical is determined based on its concentration providing $50 \%$ inhibition $\left(\mathrm{IC}_{50}\right)$, which is the value of the concentration of the sample to cause $50 \%$ inhibition and is obtained by the interpolation from the linear regression analysis (Figure 1). In this study, different fractions of the extracts were screened for their antiscavanging activity, and it was observed that the $\mathrm{MeOH}$ extract showed the highest potential with an $\mathrm{IC}_{50}$ $10.87 \mu \mathrm{g} / \mathrm{mL}$ scavenging activity, followed by $\mathrm{nHex}$ $(74.17 \mu \mathrm{g} / \mathrm{mL})$ and $\mathrm{CHCl}_{3}(74.67 \mu \mathrm{g} / \mathrm{mL})$ with the least scavenging activity. Though, the results are below that of the standard; Ascorbic acid AA with $\mathrm{IC}_{50} 4.50 \mu \mathrm{g} / \mathrm{mL}$ (Table 4). This activity might be due to the presence of phenolics and flavonoids and other secondary metabolites present in the $\mathrm{MeOH}$ extract that are known potent antioxidants, and taking into consideration, $C$. adenocaule belong to the Vitaceae family which are known for their potent antioxidant principles (Murias et al., 2005; Piotrowska et al., 2012; Rivière et al., 2012). Akinwunmi and colleagues, reported a DPPH scavenging activity of $\mathrm{IC}_{50} 38.42 \mu \mathrm{g} / \mathrm{mL}$ for the ethanol root extract of Cissus adenocaule with the root total phenolic and flavonoid content to be $182 \pm 0.38 \mathrm{mg} / \mathrm{g}$ TAE (Tannic acid equivalent) and $103 \pm 0.42 \mathrm{mg} / \mathrm{g}$ QE (Quercetin equivalent) [Akinwunmi et al., 2015].

The use of the plant as an antimicrobial agent in the ethnomedicinal space cannot be overemphasized, as they continued to be used to date. This augments their exploitations for the discovery of lead and novel molecules for antimicrobial drug discovery. They provide starting materials and derivatives that are employed as ligands in the drug discovery and development process. This study explored the antimicrobial activity of the $C$. adenocaule root extracts (Table 4). The n-Hexane extract was completely inactive against the test organism. The $\mathrm{CHCl}_{3}$ extract was active at $100 \mathrm{mg} / \mathrm{ml}$ and showed good activity against $E$. coli $(24.00 \pm 0.15)$ and moderate activity against Staph. aureus (12.5 \pm 0.18$)$. The $\mathrm{MeOH}$ extract showed poor activity against the test organism. This result is inconsonant with an earlier report by Hamil and colleagues on the activity of $\mathrm{MeOH}$ root extract of $C$. adenocaule on E. coli. P. aeruginosa and Staph. aureus (Hamill et al., 2003).

\section{CONCLUSION}

The present study undertook the phytochemical screening, isolation, and characterization of chemical compounds present in the methanol root extract of $C$. adenocaule, as well as, determination of their antioxidant and antibacterial activity. Methanol presents the best extraction solvent in terms of percentage yield. Flavonoids, alkaloids, carbohydrates and glycoside, saponins, and tannins were present while anthraquinone were absent. In the chloroform and hexane extracts; anthraquinones and flavonoids were absent, with carbohydrates also absent in the hexane extracts. In the assessment of the biological properties, the antibacterial sensitivity assay showed Chloroform to have activity against E. coli and moderate against Staph. aureus at $100 \mathrm{mg} / \mathrm{ml}$ respectively, while poor activity was recorded with the Methanol and n-Hexane extract. The DPPH antioxidant assay revealed the free radical scavenging activity, Methanol extract yields the best result with an $\mathrm{IC}_{50}$ of $10.87 \mu \mathrm{g} / \mathrm{ml}$. The results from this study add to the existing literature on $C$. adenocaule with scientific evidence into its biological properties.

Acknowledgments: The authors will like to acknowledge Mr. Namadi Sanusi of the Department of Biological science, Ahmadu Bello University, Zaria, Nigeria for the collection and identification of the plant materials.

Funding: This research did not receive any specific grant from funding agencies in the public, commercial, or not-for-profit sectors.

Conflict of interest: The authors declare no conflict of interest.

\section{REFERENCES}

Akinwunmi, K. F., Ajala, V. O., \& Oyedapo, O. O. (2015). Evaluation of antioxidant capacity and membrane stabilizing potential of stem and root of Cyphospenna adenocaulis (Steud). African Journal of Biotechnology, 14(21). https://doi.org/10.5897/ajb2015.14490

Bello, O. M., Jagaba, S. M., Bello, O. E., Ogbesejana, A. B., Dada, O. A., Adetunji, C. O., \& Abubakar, S. M. (2019). Phytochemistry, pharmacology and perceived health uses of non-cultivated vegetable Cyphostemma adenocaule (Steud. ex A. Rich.)Desc. ex Wild and R.B. Drumm: A review. In Scientific African (Vol. 2) https://doi.org/10.1016/j.sciaf.2019.e00053

Brain, KR and Turner, T. (1975). The practical evaluation of phytopharmaceuticals. J. Soc. Cosmetic Chemists, 551, 4-9.

Brand-Williams, W., Cuvelier, M. E., \& Berset, C. (1995). Use of a free radical method to evaluate antioxidant activity. In $L W T$ 
- Food Science and Technology (Vol. 28, Issue 1). https://doi.org/10.1016/S0023-6438(95)80008-5

Do, Q. D., Angkawijaya, A. E., Tran-Nguyen, P. L., Huynh, L. H., Soetaredjo, F. E., Ismadji, S., \& Ju, Y. H. (2014). Effect of extraction solvent on total phenol content, total flavonoid content, and antioxidant activity of Limnophila aromatica. Journal of Food and Drug Analysis, 22(3). https://doi.org/10.1016/j.jfda.2013.11.001

Evans, W. C. (2009). Trease and Evans' Pharmacognosy: Sixteenth Edition. Trease and Evans' Pharmacognosy: Sixteenth Edition, 1-603.

Galm, U., \& Shen, B. (2007). Natural Product Drug Discovery: The Times Have Never Been Better. Chemistry and Biology, 14(10). https://doi.org/10.1016/j.chembiol.2007.10.004

Hamill, F. A., Apio, S., Mubiru, N. K., Bukenya-Ziraba, R., Mosango, M., Maganyi, O. W., \& Soejarto, D. D. (2003). Traditional herbal drugs of Southern Uganda, II: Literature analysis and antimicrobial assays. Journal of Ethnopharmacology, 84(1). https://doi.org/10.1016/S03788741(02)00289-1

Hamilton, G. R., \& Baskett, T. F. (2000). In the arms of morpheus: The development of morphine for postoperative pain relief. In Canadian Journal of Anesthesia (Vol. 47, Issue 4). https://doi.org/10.1007/BF03020955

Igbinosa, O. O., Igbinosa, E. O., \& Aiyegoro, O. A. (2009). Antimicrobial activity and phytochemical screening of stem bark extracts from Jatropha curcas (Linn). African Journal of Pharmacy and Pharmacology, 3(2).

Iwu, M. M. (2014). Handbook of African medicinal plants, second edition. In Handbook of African Medicinal Plants, Second Edition. https://doi.org/10.1201/b16292

Joo, Y.-E. (2014). Natural Product-Derived Drugs for the Treatment of Inflammatory Bowel Diseases. Intestinal Research, 12(2). https://doi.org/10.5217/ir.2014.12.2.103

Markham, K. (1982). Techniques of flavonoid identification. Academic Press.

Murias, M., Jäger, W., Handler, N., Erker, T., Horvath, Z., Szekeres, T., Nohl, H., \& Gille, L. (2005). Antioxidant, prooxidant and cytotoxic activity of hydroxylated resveratrol analogues: Structure-activity relationship. Biochemical Pharmacology, 69(6).
Newman, D. J., Cragg, G. M., \& Snader, K. M. (2003). Natural products as sources of new drugs over the period 1981-2002. In Journal of Natural Products (Vol. 66, Issue 7). https://doi.org/10.1021/np0300961

Piotrowska, H., Kucinska, M., \& Murias, M. (2012). Biological activity of piceatannol: Leaving the shadow of resveratrol. In Mutation Research - Reviews in Mutation Research (Vol. 750, Issue 1). https://doi.org/10.1016/j.mrrev.2011.11.001

Rivière, C., Pawlus, A. D., \& Mérillon, J. M. (2012). Natural stilbenoids: Distribution in the plant kingdom and chemotaxonomic interest in Vitaceae. In Natural Product Reports (Vol. 29, Issue 11) https://doi.org/10.1039/c2np20049j

Sofowora, A. (1996). Research on medicinal plants and traditional medicine in Africa. Journal of Alternative and Complementary Medicine, 2(3). https://doi.org/10.1089/acm.1996.2.365

Truong, D. H., Nguyen, D. H., Ta, N. T. A., Bui, A. V., Do, T. H., \& Nguyen, H. C. (2019). Evaluation of the use of different solvents for phytochemical constituents, antioxidants, and in vitro anti-inflammatory activities of severinia buxifolia. Journal of Food Quality, 2019. https://doi.org/10.1155/2019/8178294

Usman, A., Abdulrahman, F. I., \& Usman, A. (2009). Qualitative phytochemical screening and in vitro antimicrobial effects of methanol stem bark extract of Ficus thonningii (Moraceae). African Journal of Traditional, Complementary and Alternative Medicines, 6(3). https://doi.org/10.4314/ajtcam.v6i3.57178

Vishnoi, N. K. (2009). Advanced practical organic chemistry. (3 ${ }^{\text {rd }}$ ed.) Vikas Publication House Pvt Ltd

WHO | WHO traditional medicine strategy. (2017). WHO http://www.who.int/medicines/publications/traditional/policy/ en/

Wickens, G. E., \& Burkill, H. M. (1986). The Useful Plants of West Tropical Africa. Kew Bulletin, 41(2). https://doi.org/10.2307/4102963

Yakubu, A. H., Ibrahim, I., bababe, A. bukar, Yesufu, H., \& Tom, mohammed G. (2020). A Natural Triglyceride from the Methanol Root Extract of Cyphostemma Adenocaule (Steud. Ex A. Rich.) Wild \& R.B.Drumm. https://doi.org/10.26434/CHEMRXIV.13296539.V1 